Under these circumstances a chest $x$ ray is mandatory to exclude a haemothorax. Late clotted haemothorax, once detected, requires an early thoracotomy for complete clearance and best long term results.

We thank Mrs Christina Hill and Mr Farid Khan in their help in preparing this paper.

Toombs BD, Sandler CM, Lester RG. Computed tomography of chest trauma. Radiology 1981;140:733-8.

Coselli J, Mattox KL, Beall A. Re-evaluation of early evacuation of clotted hemothorax. Am Surg 1984;50:21

Milfield DJ, Mattox KL, Beall AC. Early evacuation of clotted hemothorax. Am J Surg 1978;136:686-92.

4 Condon R. Clotted hemothorax. Surg Gynecol Obstet 1968;126:505

5 Mancini M, Smith LM, Nein A, Buechter K. Early evacuation of clotted blood in hemothorax using thoracoscopy: case reports. J Trauma 1993;34:144-7.

6 Feliciano DV. The diagnostic and therapeutic approach to chest trauma. In: Loop FD, McLaughlin JS, eds. Semin chest trauma. In: Loop FD, McLaugh

7 Burford H, Parker EF, Samson PC. Early pulmonary decortication in the treatment of post traumatic empyema. Ann rtication in the treat
Surg $1945 ; 122: 163$.

8 Jones PN. Spontaneous hemopneumothorax: with reference to the use of streptokinase and streptodornase. Ann Intern Med 1953;39:907-14

9 McGarry GW. A case of coagulated haemothorax treated by intrapleural Varidase. Scot Med J 1988;33:268-9.
10 Helling GS, Gyles NR, Eisenstein CL, Sorracco CA. Complications following blunt and penetrating injuries in 216 victims of chest trauma requiring tube thoracostomy. J Trauma 1989;29:1367-70.

11 Cordice JWV, Cabezon J. Chest trauma with pneumothorax and hemothorax. J Thorac Cardiovasc Surg 1965;50:316.

12 Maloney JV. The conservative management of traumatic hemothorax. Am J Surg 1957;93:533.

13 Beall AC, Bricker DL, Crawford HW, Noon GP, DeBakey ME. Considerations in the management of penetrating thoracic trauma. J Trauma 1968;8:408.

14 Miller JM. Surgical principles involved in the clinical use of streptokinase and streptodornase. Postgrad Med 1952;11: 188-95.

15 Miller JM. The treatment of haemothorax with particular reference to the use of streptokinase and streptodornase. US Armed Forces Med J 1952;3:1061-70.

16 Sherry S. The use of streptokinase and streptodornase in the treatment of hemothorax. J Thorac Surg 1950;20:393417.

17 French SW. Limited thoracotomy and enzymatic therapy in the treatment of early clotted hemothorax. US Armed Forces Med J 1958;9:949-56.

18 Jerjes-Sanchez C, Ramirez-Rivera A, Elizal de JJ, Delgado $\mathrm{R}$, Cicero R, Ibarra-Perez C, et al. Intrapleural fibrinolysis with streptokinase as an adjunctive treatment in hemothorax and empyema: a multicentre study. Chest 1996;109: 1514-19.

19 Moghissi K. Chest injuries and their management. In: Essentials of thoracic cardiac surgery. London: Heinemann, 1986:48-66.

\title{
Out of hospital cardiac arrest and associated injury
}

\author{
Andrew I Jones, M James Stuart, Alastair J Gray
}

\begin{abstract}
Three patients are described who sustained injuries around the time of a collapse that led to out of hospital cardiac arrest. In this group of patients the importance of taking a complete medical history and recording the circumstances of the syncopal episode cannot be overemphasised. If cardiac output is successfully restored the possibility of occult traumatic injury must be considered in high risk patients.

( Accid Emerg Med 1998;15:191-192)
\end{abstract}

Keywords: cardiac arrest; resuscitation; occult trauma

In the immediate aftermath of a successfully resuscitated out of hospital cardiac arrest the presence of an injury may easily be overlooked. We present three cases which illustrate this point.

Case 1

A 65 year old male sustained a cardiac arrest in the street. Bystander basic life support was given immediately. The extended trained ambulance crew found him to be in ventricular fibrillation. Defibrillation restored sinus rhythm.

On arrival at the accident and emergency (A\&E) department he was drowsy but responding to questions. He remained in sinus rhythm with a systolic blood pressure of 100 $\mathrm{mm} \mathrm{Hg}$. He appeared able to move only his shoulder girdle muscles. Bruising to the forehead was noted.
Radiography of the neck showed advanced ankylosing spondylitis with a fracturedislocation. He was stabilised on the intensive care unit but he died the following day.

\section{Case 2}

A 63 year old male sustained an out of hospital cardiac arrest. A nurse bystander gave basic life support. The attending extended trained ambulance crew found him to be in ventricular fibrillation, and sinus rhythm was rapidly restored by defibrillation. At this stage he was localising to pain and had a Glasgow coma score of 8. Examination at the A\&E department showed bruising of his right temple. Radiography of his skull was normal but in view of his persisting reduced level of consciousness computed tomography was performed and showed frontal and temporal contusions. He was subsequently intubated and admitted to the neurosurgical unit. After 10 days he was discharged home.

\section{Case 3}

A 56 year old man suddenly collapsed in the street and was found to be in ventricular fibrillation by the attending ambulance crew. $\mathrm{He}$ was immediately cardioverted and cardiac output was restored.

On arrival in the A\&E department he was agitated and combative. He was maintaining his own airway and his oxygen saturation was $99 \%$ while breathing high flow oxygen. He had 
a heart rate of 150 beats $/ \mathrm{min}$ with a systolic blood pressure of $90 \mathrm{~mm} \mathrm{Hg}$. Blood glucose was $8 \mathrm{mmol} / \mathrm{l}$ on bedside testing. Electrocardiography showed a left bundle branch block pattern and a provisional diagnosis of acute myocardial infarction was made. Intravenous diamorphine and diazepam were given as the patient was proving impossible to restrain.

Further examination revealed a ragged occipital laceration, a Glasgow coma score of 7 with equal reactive pupils, and no evidence of a motor deficit. Both plantar responses were noted to be extensor. On questioning his relatives revealed that he had undergone coronary artery bypass surgery 10 years previously and was on long term warfarin treatment.

Since he had evidence of an acute head injury with significantly altered level of consciousness, urgent computed tomography of his head was performed. This revealed an occipital fracture with contra-coup contusion in the right temporoparietal region.

\section{Discussion}

Increasing numbers of patients are successfully resuscitated following prehospital cardiac arrest. ${ }^{1}$ Aftercare of these patients tends to focus on the medical aspects of the postarrest phase. Associated trauma owing to cardiopulmonary resuscitation is a well recognised phenomenon. ${ }^{2}$ Not so well recognised is coincidental injury arising as a result of the sudden syncope and fall seen in cardiac arrest. As seen in these cases, this may cause severe head and neck injury.

It is well recognised that the presence of ankylosing spondylitis predisposes to cervical cord injury after minor trauma. ${ }^{4}$ Similar injuries to the cervical cord after apparently minor trauma have also been described in patients with rheumatoid arthritis. ${ }^{5}$ This has profound implications for the prehospital and in hospital care of these patients. When sudden syncope and fall occurs in a patient with an "at risk" cervical spine, full neck immobilisation should be applied. Where no past medical history is available and signs of cranial trauma are evident, immobilisation should be applied as a precaution. Removal of this immobilisation should not be attempted until the cervical spine has been cleared by adequate imaging and normal neurological examination.

In the postarrest phase, a persisting obtunded conscious level may be attributed to hypoxic brain injury. Cases 2 and 3 show that signs of cranial trauma should raise the suspicion of direct brain injury, and computed tomography should be done. This is particularly important in patients who are on anticoagulants. ${ }^{6}$

In this group of patients the importance of taking a complete medical history and recording the circumstances of the syncopal episode cannot be overemphasised. If cardiac output is successfully restored the possibility of occult traumatic injury must be considered in high risk patients.

1 Sedgwick ML, Watson J, Dalziel K, Carrington DJ, Cobbe SM. Efficacy of out-of-hospital defibrillation by ambulance technicians using automated external defibrillators: the Heartstart Scotland project. Resuscitation 1992;24:73-87.

2 Kendall IG, Wynn SM, Quinton DN. A study of patients referred from A\&E for coroners post-mortem. Arch Emerg referred from A\&E for

3 Krischer JP, Fine EG, Davis JH, Nagel EL. Complications of cardiac resuscitation. Chest 1987;92:287-91.

4 Olerud C, Frost A, Bring J. Spinal fractures in patients with ankylosing spondylitis. Eur Spine J 1996;5:51-5.

5 Agarwal AK, Peppelman WC, Kraus DR, Eisenbeis $\mathrm{CH}$. The cervical spine in rheumatoid arthritis. BMJ 1993;306: 79-80.

6 Saab M, Gray A, Hodgkinson D, Irfan M. Warfarin and the apparent minor head injury. J Accid Emerg Med 1996;13: 208-9.
Booth Hall Children's Hospital, Manchester, UK

H S Ali

Correspondence to: Mr H Shaaban Ali, Department of Plastic Surgery, Booth Hall Children's Hospital, Manchester M9 7AA, UK

Accepted for publication 14 January 1998

\section{Ectopic pregnancy presenting with obturator nerve pain}

Hassan Shaaban Ali plained symptoms including pain anywhere from the shoulder down to the knee. (f Accid Emerg Med 1998;15:192-193)

Keywords: ectopic pregnancy; obturator nerve; referred pain

\section{Case report}

A 27 year old woman presented to the accident and emergency (A\&E) department with a two day history of pain on the inner aspect of the left thigh, which later radiated to the left groin. There was no history of trauma. She had stopped taking the contraceptive pill one month before and her last menstrual period had been eight weeks' ago. 
the intensive care unit, and another from the computed tomography scanner to the neurosurgeons in Nottingham.

The fire brigade came and informed us of a fire in the basement under the department. The department was full of smoke and we could not work in it for several hours.

Several patients were sent directly to wards and the ambulance service diverted patients to other hospitals. We opened the outpatient department and the day case unit and treated casualties there. This makeshift plan was difficult to implement. A few hours later when the fire was put out and the smoke dispersed, we returned with our patients to an undamaged department.

Before this experience we have had two fires started deliberately by patients in the department-one in a toilet and one in a waiting room. So the possibility of this, or indeed any, emergency department being unable to function for a period of time is always there. Fire is the most likely cause but explosions, building collapse, electrical failure, flooding, and violent affrays are others. Working in over 20 hospitals over the last 35 years, AF-M has seen all of these, but only the smoke from this fire was serious enough to cause our emergency department to be closed.)

We had no local plan in our hospital to deal with this contingency. We do now have such a plan and I am sure that other hospitals should follow our example to avoid being caught out.

There are no national guidelines for hospitals or accident and emergency departments to close, but the ambulance service has national guidelines for diverting all ambulances to other hospitals in circumstances such as these. This can easily be arranged through your local ambulance service.

A mobile field hospital could in theory be provided by the armed services. This requires quite a fair sized space to set it up. Reliable sources with experience of setting up these hospitals have told us that this takes at least 48 hours. So this is not a "quick" option, but an alternative if the emergency department is out of action.

A FRASER-MOODIE

Consultant in Accident and Emergency Medicine D HUGHES

Registrar in Accident and Emergency Medicine, Emergency Departmen Derbyshire Royal Infirmary London Road, Derby DE1 2QY

\section{Foreign body removal from children's noses}

EDITOR,-Nasal foreign bodies are a common problem in children attending accident and emergency departments and general practice surgeries. The cooperation required is often not forthcoming as most patients are under 5 years. Instrumentation requiring restraint, sedation, or even general anaesthesia are frequently necessary. This approach may be avoided by using the positive pressure technique described below, which can be used by the parent to quickly and safely remove a nasal foreign body. ${ }^{1-3}$

A history is taken from the parent and child to determine the nature of the foreign body and which nostril is involved. If the child is cooperative, the nares can be examined to locate the foreign body but this is not absolutely necessary if there is a clear indication of which nostril is involved.

Parents are instructed to sit the child on their knee, with the nostril containing the for- eign body closest to the parent. The parent should then close the "patent" nostril using a finger and tell the child that they are going to give them "a great big kiss". Parents should then seal their lips around the child's and deliver a short sharp puff of air. The foreign body is usually extruded with one puff. It is worth holding a paper tissue close by as the foreign body is usually well covered with mucus. If this is unsuccessful several more attempts can be made without any harm. Each additional "puff" may dislodge the foreign body a little further.

The author has used this technique in over 20 cases with no failures or complications. Various objects including beads, peas, pieces of bread, and even a rabbit dropping have been removed successfully. The time from insertion of the foreign body to removal by the technique does not appear to be a factor.

Despite the simplicity of this technique it seems little used. It is easily taught to parents and can be undertaken in any setting. Use of restraints, anaesthesia, and instrumentation in frightened and distressed children can be avoided.

SARAH SCHOFIELD Principal in General Practice, North Baddesley Health Centre, Norton Welch Close, Fleming Avenue, North Baddesley, Southampton SOS2 9EP

1 Backlin SA. Positive pressure technique for nasa foreign body removal in children. Ann Emer Med 1995;25:554-5.

2 Werman HA. Removal of foreign bodies of the nose. Emerg Med Clin North Am 1987;May: 253-63.

3 Cohen HA, Goldberg E, Thorev Z. Removal of nasal foreign bodies in children. Clin Pediatr (Phila) 1993;32:192.

\section{Alcohol intoxication}

EDrToR,-I read with great interest the recent letters by Tovey $e t a l$ and Denning ${ }^{2}$ regarding the alcohol content of some proprietary paediatric medications and commercially available mouthwashes. Previously I was able to highlight the potential danger to children of perfumed body sprays, ${ }^{3}$ which commonly have an alcohol content of between $70-80 \%$. A child attended the accident and emergency department having consumed the contents of a "tangerine dream" perfumed body spray. She was admitted, but fortunately came to no harm. The presentation of this brand of perfumes was extremely suggestive of a soft drink. No warning was displayed on the containers, which could easily be opened by a child. This article was picked up by several newspapers and a parenting magazine. I subsequently noticed that the company selling these products had withdrawn them from their shelves. The enormous power of the media should be harnessed whenever possible in these and similar areas to protect the most vulnerable in society.

DAVID MOORE

Specialist Registrar in Accident and Emergency Medicine, Accident and Emergency Departmen Norfolk and Norwich Hospital, Brunswick Road, Norwich NR1 $3 S R$

1 Tovey C, Rana PSJB, Anderson DJ. Alcohol intoxication in a toddler. J Accid Emerg Med intoxication in

2 Denning Z. More alcohol. J Accid Emerg Med 1998;15:70.

3 Moore D, Gronow R, McCabe M. Small children may consume perfumed body spray after mistaking them for soft drinks. BMJ 1996; 313:757.

\section{Fitness to drive}

EDIToR,-Each year there are more than 15 million visits to UK accident and emergency ( $A \& E$ ) departments. ${ }^{1}$ Many sustain injuries, suffer from medical conditions, or have had drugs administered to them that temporarily impair the patient's ability to drive safely. Yet it is rare to hear discussion of this issue with the patient. A small prospective audit of 21 patients of driving age who were discharged from the department after the application of a limb plaster failed to demonstrate any written advice as to whether they should drive or not.

It is clear that a doctor has a legal duty to warn those patients whose driving may be impaired not to do so and to record this in the notes. ${ }^{2}$ Patients who fail to take the advice of the doctor will probably invalidate their insurance. ${ }^{3}$ The responsibility for the provision of advice for this patient group lies with each A\&E department. "Suitability to drive" is now covered in the senior house officer teaching programme.

$M$ J CLANCY P G POCKNEY Emergency Department, Level C, Southampton General Hospital, Tremona Road, Southampton SO16 6YD

1 Audit Commission. By accident or design. London: Audit Commission, 1995.

2 Montague A. Legal problems in emergency medicine. Oxford: Oxford University Press, 1996.

3 Giddins GEB, Hammerton A. Doctor, when can I drive?A medical and legal view of the implications of advice on driving after injury or operation. Injury 1996;27:495-7.

\section{Corrections}

Out of hospital cardiac arrest and associated injury by Andrew I Jones, $M$ James Stuart, Alastair J Gray ( $\mathcal{F}$ Accid Emerg Med $1998 ; 15: 191-2)$. We regret that because of a production problem the affiliations of the authors of this paper were omitted. They are as follows:

North Tyneside Health Care NHS Trust, Accident and Emergency, North Tyneside General Hospital, Rake Lane, North Shields, Tyne and Wear NE29 8NH A I Jones

Department of Emergency Medicine, Manchester Royal Infirmary M J Stuart

Department of Accident and Emergency, Stepping Hill Hospital, Stockport

A J Gray

Correspondence to: Dr Jones, Consultant.

\section{$\star \star \star \star$}

Implementing the Ottawa ankle rules in an Asian accident and emergency medicine department. What potential for saving? $\mathcal{F}$ Accid Emerg Med 1998;15:132). We regret that there was a spelling error in the first author's name: this should have been Rainer rather than Stainer. 